\title{
Risk of hip fracture among older people using antihypertensive drugs: a nationwide cohort study
}

\author{
Sabine Ruths ${ }^{1,2^{*}}$, Marit S. Bakken ${ }^{1,3}$, Anette H. Ranhoff ${ }^{3,4}$, Steinar Hunskaar ${ }^{1,5}$, Lars B. Engesæter ${ }^{6,7}$ \\ and Anders Engeland ${ }^{1,8}$
}

\begin{abstract}
Background: Many people with a high risk of hip fracture have coexisting cardiovascular diseases. We aimed to examine associations between exposure to antihypertensive drugs and the risk of hip fracture among older people.

Methods: We conducted a cohort study of the 906,422 people born before 1945 and living in Norway in 2005. We obtained information on all prescriptions of antihypertensive drugs dispensed (the Norwegian Prescription Database) in 2004-2010 and the dates of primary hip fractures (the Norwegian Hip Fracture Registry) in 2005-2010. We compared the incidence rates of hip fracture during the time people were exposed and unexposed to antihypertensive drugs by calculating the standardized incidence ratio (SIR).

Results: Altogether, 39,938 people experienced a primary hip fracture (4.4\%). The risk of hip fracture was decreased among people exposed to thiazides (SIR 0.7, 95 \% confidence interval (CI) 0.6-0.7), beta-blockers (SIR 0.7, 95 \% Cl 0.7-0.8), calcium channel blockers (SIR 0.8, $95 \%$ Cl 0.8-0.8), angiotensin II receptor blockers (SIR 0.8, 95 \% Cl 0.7-0.8), ACE inhibitor/thiazide combination products (SIR 0.7, $95 \%$ Cl 0.6-0.7) and angiotensin II receptor blocker/thiazide combination products (SIR 0.6, $95 \% \mathrm{Cl}$ 0.6-0.6). Use of loop diuretics and ACE inhibitors (plain products) was associated with increased fracture risk in people born after 1924, and with decreased risk in those born before 1925. The protective associations were stronger among exposed men than among exposed women for all drugs except loop diuretics. The SIRs decreased with increasing age among exposed people, except for thiazides and angiotensin II receptor blockers.

Conclusions: We found a reduced risk of hip fracture associated with overall use of most antihypertensive drugs, but an increased risk with loop diuretics and ACE inhibitors among people younger than 80 years and in new users of loop diuretics. This may have great impact at the population level, because the use of antihypertensive drugs is widespread in people at risk of hip fracture. Clinical studies are needed to further explore these associations.
\end{abstract}

Keywords: Older people, Hip fracture, Antihypertensive drugs, Bone mineral density, Fall

\section{Background}

Hip fractures represent critical events that seriously affect morbidity and mortality [1]. The risk of hip fracture increases with age; with estimated lifetime risk of $30 \%$ for women and $18 \%$ for men in Norway at the age of 50 years [2]. Many older people with osteoporosis have coexisting cardiovascular disease such as hypertension, ischemic heart

\footnotetext{
* Correspondence: sabine.ruths@uib.no

'Department of Global Public Health and Primary Care, University of Bergen, PO Box 7804, N-5020 Bergen, Norway

${ }^{2}$ Research Unit for General Practice, Uni Research Health, Bergen, Norway Full list of author information is available at the end of the article
}

disease, heart failure and stroke. Both high blood pressure and systolic hypotension have been associated with falls, reduced bone mineral density (BMD) and hip fracture [3-6].

Antihypertensive drugs are prescribed to more than half the people aged 60 years and older in Europe and the United States, in accordance with recommendations of broad risk assessments, lower limits for blood pressure and ambitious therapeutic goals [7-9]. While observational studies indicate an increased risk of falls and hip fracture in older people after initiating antihypertensive drugs [10-12], meta-analyses have revealed no 
associations between long-term treatment and falls [13, 14]. A review of pharmacology, mechanisms and possible effects on BMD revealed beneficial effects of thiazides (reduced renal calcium depletion, direct stimulation of osteoblasts), beta-blockers (inhibition of beta-adrenergic receptor in bone), and angiotensin-converting enzyme (ACE) inhibitors (inhibition of ACE in local renin-angiotensin-aldosterone system); no effect in either direction of angiotensin II receptor blockers (direct blockade of angiotensin II receptor) and calcium channel blockers (inhibition of voltage-gated calcium channel); negative effects of loop diuretics (increased renal calcium depletion, risk of falls) [15].

Previous studies of associations between antihypertensive drug use and hip fracture have focused mainly on diuretics and beta-blockers. While research involving renin-angiotensin-aldosterone active agents and calcium channel blockers is limited and diverging, combination products have not yet been considered. Because these drugs are widely used, it is important to compare their impact with other antihypertensive drug groups to inform prescribing decisions for older people at risk of osteoporosis and hip fracture. Based on the Norwegian Prescription Database and the Norwegian Hip Fracture Registry, we conducted a nationwide cohort study to examine associations between exposure to antihypertensive drugs (plain and combination products) and the risk of hip fracture among people 60 years and older.

\section{Methods}

We conducted a cohort study based on data extracted from three national registries: the Norwegian Prescription Database (NorPD) [7], the Norwegian Hip Fracture Registry [16] and the Central Population Registry [17]. Registries with clinical data on comorbidity were not available. The model has previously been described in detail [18].

\section{Registries}

The NorPD is a central health registry that contains information on all dispensed prescriptions at pharmacies to individual patients treated in ambulatory care in Norway since January 2004 [19]. For the purpose of this study, we extracted data on all prescriptions of antihypertensive drugs (defined below), dispensed from 1 January 2004 until 31 December 2010, by the items' Anatomical Therapeutic Chemical (ATC) system code and drug volume by defined daily dose (DDD) to individual patients [20]. Prescriptions dispensed during 2004 were used to identify current drug users when the study period started on 1 January 2005. The NorPD does not capture individual information on drugs dispensed to people staying in hospitals or nursing homes (about 12,000 and 40,000 at any time). Further, the NorPD does not comprise clinical data. Reimbursement codes linked to diagnoses became available from 2009; because they were not validated against clinical data, we chose not to include this information.

Since January 2005, all hospitals in Norway performing operations for hip fracture have reported information on such surgery to the Norwegian Hip Fracture Registry [16]. The data extracted for this study comprised the date of first hip fracture during the study period (hereafter referred to as primary hip fracture), or the date of surgery in case of missing information, for the period from 1 January 2005 until 31 December 2010. Although the registry also contains fractures among patients in nursing homes and hospitals, these individuals cannot be identified in the study cohort.

The Central Population Registry contains demographic information on the entire population of Norway since 1960 [17]. We extracted data on the year of birth, sex and the date of death or emigration if applicable.

The variables selected from these three registries were merged, using the unique 11-digit personal identity number assigned to all residents of Norway after 1960. Data linkage was performed by a trusted third party (Statistics Norway).

\section{Study cohort}

The study population comprised all people born before 1945 and living in Norway on 1 January 2005. Study subjects were categorized according to birth year; $<1915$, 1915-1924, 1925-1934, or 1935-1945. Follow-up continued until the first of any censoring events, including the day of any first hip fracture, emigration or death, or until the end of the study period. The study period lasted from 1 January 2005 to 31 December 2010.

\section{Antihypertensive drugs}

The following medications were considered:

- C03A, Thiazides: hydrochlorthiazide, bendroflumethiazide/potassium

- C03C, Loop diuretics: furosemide, bumetanide

- C07, Beta-blockers: propanolol, sotalol, metoprolol, atenolol, bisoprolol, esmolol, labetolol, carvedilol

- C08, Calcium channel blockers: amlodipine, felodipine, isradipine, nifedipine, nimodipine, lercanidipine, verapamil, diltiazem

- C09A, ACE inhibitors: captopril, enalapril, lisinopril, ramipril, trandolapril

- C09B, ACE inhibitor/thiazide: enalapril/thiazide, lisinopril/thiazide, zofenopril/thiazide

- C09C, Angiotensin II receptor blockers: losartan, eprosartan, valsartan, irbesartan, candesartan, telmisartan, olmesartan medoxomil

- C09D, Angiotensin II receptor blockers/thiazide: losartan/thiazide, eprosartan/thiazide, valsartan/ 
thiazide, irbesartan/thiazide, candesartan/thiazide, telmisartan/thiazide, olmesartan medoxomil/thiazide

C02, Antihypertensives (moxonidine, doxazosin, hydralazine, bosentan, ambrisentan) were not included because they were rarely used in "common" patients.

\section{Drug exposure}

The NorPD does not include information on whether or when the dispensed drugs were consumed; hence, we had to make assumptions on drug exposure. The DDD is the assumed average maintenance dose per day for a drug used for its main indication among adults [20]. Since antihypertensive drugs are prescribed primarily for long-term use on a daily basis, the number of days corresponding to the number of DDDs dispensed was used as proxy for the number of person-days exposed. We assumed that people started using the drugs on the day they were dispensed.

We defined overall use as all person-days exposed within the study period (on-treatment definition of exposure). No gap period was included. We defined recently started use as the first 14 days of drug exposure after a 365-day washout period.

\section{Statistical analysis}

We compared the incidence of primary hip fracture during the person-days exposed and unexposed to antihypertensive drugs in the study period by calculating the standardized incidence ratio (SIR) [21]. An SIR >1 indicates an increased risk of hip fracture associated with exposure, while an SIR $<1$ indicates a decreased risk. We adjusted the SIR for sex, birth year and time period (divided into 2-month intervals).

For SIR values based on fewer than 100 observed primary hip fractures among exposed people, we calculated exact $95 \%$ confidence intervals (CI) assuming a Poisson distribution of the observed number of hip fractures $(\mathrm{O})$ among exposed people, estimating the mean by the expected number of hip fractures among the exposed people. When the observed numbers of hip fractures among exposed people exceeded 100, the $95 \%$ CI values were approximated by the following formula: [SIR $\cdot \exp$ $(-1.96 \sqrt{ } \mathrm{O})$, SIR. $\exp (1.96 \sqrt{\mathrm{O}})]$.

To calculate the attributable effect of exposure to antihypertensive drugs on hip fractures, we divided the observed minus the expected number of fractures during the number of person-days exposed to these drugs by the observed number of fractures in the study population. We performed analysis using IBM SPSS 19 (PASW Statistics for Windows, SPSS Inc, Chicago, IL, USA).

\section{Ethics and approvals}

The Regional Committee for Medical and Health Research Ethics, REC West (138/07) and the Norwegian
Data Inspectorate (08/00133) approved the study. We obtained permission from the Norwegian Institute of Public Health regarding data from the Norwegian Prescription Database (08/2173); from the Norwegian Arthroplasty Register regarding data from the Norwegian Hip Fracture Registry (9 June 2009); and from Tax Norway regarding data from the Central Population Registry (2008/612430). The Norwegian Directorate of Health granted an exemption from the duty of confidentiality regarding linkage of data from the three databases (08/1843). Linkage was performed by a trusted third party (Statistics Norway).

\section{Results}

The study cohort comprised 906,422 people (56 \% women) with a mean age of 72.8 years (standard deviation (SD) 8.9 years) on 1 January 2005. The distribution by birth year and sex is shown in an additional file [see Additional file 1]. The mean follow-up was 5.2 (SD 1.6) years. During the study period, 218,775 people died (53\% women) and 4949 emigrated ( $44 \%$ women).

The drugs most frequently used were angiotensin II receptor blockers $(30.5 \%$ of the study cohort; plain products: $16.5 \%$, combination products: $14.0 \%$ ), beta-blockers (29.8 \%) and calcium channel blockers (21.6 \%). More women used diuretics and angiotensin II receptor blockers/ thiazide, and fewer women used beta-blockers and ACE inhibitors, as compared with men. Sex differences for other drug groups were minor. The use of antihypertensive drugs decreased with age (Table 1 ).

Altogether, 39,938 (4.4\%) people experienced a primary hip fracture during the study period. On average, $72 \%$ were women; the proportion increased with age, from 63 \% (born 1934-1944) to $81 \%$ (born <1915). The mean age at the time of fracture was 83.0 years. People born in 1925-1934 or 1915-1924 experienced most fractures (Table 2).

Table 3 shows that exposure to thiazides (SIR 0.7, $95 \%$ CI 0.6-0.7), beta-blockers (SIR 0.7, $95 \%$ CI 0.7-0.8), calcium channel blockers (SIR 0.8, $95 \% \mathrm{CI}$ $0.8-0.8$ ), angiotensin II receptor blockers (SIR 0.8, $95 \%$ CI 0.7-0.8), combination products containing ACE inhibitor/thiazide (SIR 0.7, $95 \%$ CI 0.6-0.7) and angiotensin II receptor blocker/thiazide (SIR 0.6, $95 \%$ CI 0.6-0.6) was associated with decreased risk of hip fracture. Use of loop diuretics and ACE inhibitors was associated with increased risk of fracture if born after 1924, and with decreased risk if born before 1925. The SIRs were lower among exposed men than among exposed women for all drugs except loop diuretics. Generally, the SIRs decreased with increasing age among exposed people, except for thiazides and angiotensin II receptor blockers (Table 3).

Subanalysis for recently started drug treatment revealed increased risk of hip fracture during the first 14 days of 
Table 1 Percentage of people in Norway born before 1945 who purchased antihypertensive drugs during 2005-2010

\begin{tabular}{|c|c|c|c|c|c|c|c|}
\hline & \multirow{2}{*}{$\begin{array}{l}\text { Total cohort } \\
n=906,422\end{array}$} & \multicolumn{2}{|l|}{ By sex } & \multicolumn{4}{|c|}{ By birth cohort } \\
\hline & & Women & Men & 1935-1944 & 1925-1934 & 1915-1924 & $<1915$ \\
\hline & & $n=506,568$ & $\mathrm{n}=399,854$ & $n=397,761$ & $n=294,952$ & $n=183,967$ & $n=29,742$ \\
\hline Thiazide & 6.2 & 7.1 & 5.2 & 2.8 & 2.3 & 1.0 & 0.1 \\
\hline Loop diuretic & 17.9 & 19.4 & 15.9 & 5.0 & 7.1 & 5.3 & 0.5 \\
\hline Beta blocker & 29.8 & 28.6 & 31.3 & 12.1 & 11.6 & 5.8 & 0.3 \\
\hline Calcium channel blocker & 21.6 & 21.5 & 21.6 & 8.9 & 8.4 & 4.1 & 0.2 \\
\hline ACE inhibitor & 14.0 & 12.4 & 16.0 & 5.4 & 5.4 & 2.9 & 0.3 \\
\hline ACE inhibitor/Thiazide & 3.8 & 2.1 & 1.7 & 1.7 & 1.4 & 0.7 & $<0.1$ \\
\hline Angiotensin II receptor blocker & 16.5 & 16.8 & 16.1 & 7.9 & 6.0 & 2.4 & 0.1 \\
\hline Angiotensin II receptor blocker/Thiazide & 14.0 & 8.1 & 5.9 & 7.0 & 5.1 & 1.8 & 0.1 \\
\hline
\end{tabular}

Individuals may have purchased more than one antihypertensive drug type

treatment with loop diuretics (all: SIR 1.6, $95 \%$ CI 1.31.9; women: SIR 1.6, 95 \% CI 1.2-2.0; men: SIR 1.6, $95 \%$ CI 1.1-2.3). The number of hip fractures during the first 14 days of treatment was small $(n=257)$ and revealed no statistically significant results for other drug classes (Table 4).

Attributable effect for overall exposure was estimated at $-3.6 \%$ for angiotensin II receptor blockers/ thiazide, $-3.5 \%$ for beta-blockers, and $-3.4 \%$ for calcium channel blockers (Table 3 ).

\section{Discussion}

In this registry-based cohort study including the entire population of Norway aged 60 years and older, we found a reduction in risk of hip fracture associated with use of most antihypertensive drugs. However, fracture risk among users of loop diuretics and plain ACE inhibitors was increased in people younger than 80 years, and in new users of loop diuretics.

\section{Methodological considerations}

The nationwide cohort design is suitable to compare people exposed and non-exposed to antihypertensive drugs with regard to the relatively infrequent outcome, hip fracture, without being prone to selection and recall bias. The health registries provided us a unique opportunity to link complete data on all antihypertensive drugs purchased by a large unselected community-dwelling older population

Table 2 Number (n) and incidence rate (\%) of hip fracture among people in Norway during 2005-2010

\begin{tabular}{|c|c|c|c|c|c|c|c|c|}
\hline \multirow[t]{3}{*}{ Hip fractures } & \multicolumn{8}{|c|}{ Birth year } \\
\hline & \multicolumn{2}{|c|}{$1935-1944$} & \multicolumn{2}{|c|}{$1925-1934$} & \multicolumn{2}{|c|}{ 1915-1924 } & \multicolumn{2}{|c|}{$<1915$} \\
\hline & $\mathrm{n}$ & $\%$ & $\mathrm{n}$ & $\%$ & $n$ & $\%$ & $\mathrm{n}$ & $\%$ \\
\hline All $(n=39,938)$ & 4904 & 1.2 & 13,322 & 4.5 & 18,599 & 10.1 & 3153 & 10.6 \\
\hline Women $(n=28,883)$ & 3086 & 1.5 & 9269 & 5.6 & 13,982 & 11.8 & 2546 & 11.4 \\
\hline Men $(n=11,055)$ & 1818 & 0.9 & 4053 & 3.1 & 4577 & 7.0 & 607 & 8.3 \\
\hline
\end{tabular}

with all primary hip fractures registered in Norway, and the 6-year follow-up period yielded a high number of cases.

However, the databases have some limitations. The NorPD lacks individual information on medications dispensed to people staying in nursing homes (predominantly long-term care) and hospitals (mostly short stays), leading to systematic misclassification as drug non-users. Because frail old people in nursing homes are particularly prone to both treatment with antihypertensive drugs and hip fracture [22, 23], bias from immeasurable exposure time probably caused underestimation of associations among exposed people. The Norwegian Hip Fracture Registry comprised about $90 \%$ of all hip fracture operations in Norway [24], with somewhat lower completeness during the first years. Unfortunately, clinical information regarding diagnoses, BMD, functional level, socioeconomic factors and life style was not available from the included or any other registry. This hampered adjustments for potentially confounding factors such as fall-riskrelated comorbidities (FRICs), i.e. heart failure, ischemic heart disease, chronic obstructive lung disease, dementia, depression, Parkinson's disease and stroke. Many older people treated with antihypertensive drugs probably use other drugs concomitantly, e.g. fall-risk-increasing drugs (FRIDs) such as other cardiovascular drugs, psychotropics, opioids and systemic steroids. However, with the timevarying exposure used in the analysis (SIR), matching exposure periods for other drugs was not possible. We consider the time-varying exposure a major strength of our study, as the alternative, fixed exposure, would have led to extensive and unmeasurable misclassification yielding unreliable results. In Norway, antihypertensive drugs are mainly prescribed for hypertension (88-99\% of overall drug volume); however about $40 \%$ of ACE inhibitors (plain products) and beta-blockers are prescribed for conditions such as heart failure and ischemic heart disease [8], and loop diuretics are mainly used for fluid retention. Because many drugs have several different indications, we 
Table 3 Comparison of number of hip fractures (n) during exposed and unexposed person-time $\mathrm{a}^{\mathrm{a}}$ (SIR, 95 \% Cl)

\begin{tabular}{|c|c|c|c|c|c|c|c|c|c|c|c|c|c|c|c|}
\hline \multirow{3}{*}{ Exposed person-days (DDD) } & \multicolumn{2}{|c|}{ Total cohort } & \multicolumn{4}{|c|}{ By sex } & \multicolumn{8}{|c|}{ By birth cohort } & \multirow{3}{*}{$\begin{array}{l}\text { Attributable } \\
\text { effect (\%) }\end{array}$} \\
\hline & \multirow[b]{2}{*}{$\mathrm{n}$} & \multirow[b]{2}{*}{$\operatorname{SIR}(\mathrm{Cl})$} & \multicolumn{2}{|c|}{ Women } & \multicolumn{2}{|l|}{ Men } & \multicolumn{2}{|c|}{$1935-1944$} & \multicolumn{2}{|c|}{$1925-1934$} & \multicolumn{2}{|c|}{$1915-1924$} & \multicolumn{2}{|c|}{$<1915$} & \\
\hline & & & $\mathrm{n}$ & $\mathrm{SIR}(\mathrm{Cl})$ & $\mathrm{n}$ & $\mathrm{SIR}(\mathrm{Cl})$ & $n$ & SIR (C)I) & $n$ & $\mathrm{SIR}(\mathrm{Cl})$ & $n$ & $\mathrm{SIR}(\mathrm{Cl})$ & $n$ & $\mathrm{SIR}(\mathrm{Cl})$ & \\
\hline Thiazide & 550 & $0.7(0.6-0.7)$ & 441 & $0.7(0.6-0.8)$ & 109 & $0.6(0.5-0.8)$ & 61 & $0.7(0.5-0.8)$ & 208 & $0.6(0.6-0.7)$ & 258 & $0.7(0.6-0.8)$ & 23 & $0.8(0.5-1.2)$ & -0.6 \\
\hline Loop diuretic & 4752 & $1.0(1.0-1.0)$ & 3422 & $1.0(0.9-1.0)$ & 1330 & $1.1(1.1-1.2)$ & 371 & $2.0(1.8-2.3)$ & 1538 & $1.3(1.2-1.3)$ & 2543 & $0.9(0.8-0.9)$ & 300 & $0.7(0.6-0.8)$ & 0.1 \\
\hline Beta blocker & 4074 & $0.7(0.7-0.8)$ & 3010 & $0.8(0.8-0.8)$ & 1064 & $0.7(0.6-0.7)$ & 511 & $0.9(0.9-1.0)$ & 1700 & $0.8(0.8-0.8)$ & 1757 & $0.7(0.6-0.7)$ & 106 & $0.6(0.5-0.8)$ & -3.5 \\
\hline Calcium channel blocker & 5028 & $0.8(0.8-0.8)$ & 3736 & $0.8(0.8-0.8)$ & 1292 & $0.7(0.7-0.8)$ & 642 & $1.0(0.9-1.1)$ & 1982 & $0.8(0.8-0.8)$ & 2234 & $0.7(0.7-0.8)$ & 170 & $0.7(0.6-0.8)$ & -3.4 \\
\hline ACE inhibitor & 3438 & $0.9(0.9-1.0)$ & 2351 & $1.0(0.9-1.0)$ & 1087 & $0.9(0.8-0.9)$ & 410 & $1.3(1.1-1.4)$ & 1389 & $1.1(1.0-1.1)$ & 1512 & $0.8(0.8-0.8)$ & 127 & $0.7(0.6-0.9)$ & -0.6 \\
\hline ACE inhibitor/Thiazide & 662 & $0.7(0.6-0.7)$ & 520 & $0.7(0.6-0.8)$ & 142 & $0.5(0.4-0.6)$ & 111 & $1.9(0.8-1.2)$ & 264 & $0.7(0.6-0.7)$ & 261 & $0.6(0.5-0.6)$ & 26 & $0.9(0.6-1.3)$ & -0.9 \\
\hline Angiotensin II receptor blocker & 2631 & $0.8(0.7-0.8)$ & 2041 & $0.8(0.8-0.8)$ & 590 & $0.7(0.6-0.7)$ & 411 & $0.9(0.8-1.0)$ & 1049 & $0.7(0.7-0.8)$ & 1094 & $0.8(0.7-0.8)$ & 77 & $0.8(0.6-1.0)$ & -1.9 \\
\hline Angiotensin II receptor blocker/Thiazide & 2122 & $0.6(0.6-0.6)$ & 1688 & $0.6(0.6-0.7)$ & 434 & $0.5(0.4-0.5)$ & 367 & $0.7(0.6-0.7)$ & 915 & $0.6(0.6-0.6)$ & 790 & $0.6(0.5-0.6)$ & 50 & $0.6(0.5-0.9)$ & -3.6 \\
\hline
\end{tabular}

SIR Standardized Incidence Ratio, DDD Defined Daily Dose, Attributable effect percentage of hip fractures during DDD exposure throughout the study period

${ }^{a}$ The population of Norway born before 1945 and exposed to various antihypertensive drugs in 2005-2010 (exposed person-days, DDD) 
Table 4 Recently started antihypertensive drugs; comparison of number of hip fractures during exposed and unexposed persontime $^{a}$

\begin{tabular}{|c|c|c|c|c|c|c|}
\hline \multirow{3}{*}{ Exposed person-days ( 14 days) } & \multicolumn{2}{|c|}{ Total cohort } & \multicolumn{4}{|c|}{ By sex } \\
\hline & \multirow[b]{2}{*}{$n$} & \multirow[b]{2}{*}{$\mathrm{SIR}(\mathrm{Cl})$} & \multicolumn{2}{|c|}{ Women } & \multicolumn{2}{|c|}{ Men } \\
\hline & & & $\mathrm{n}$ & $\mathrm{SIR}(\mathrm{Cl})$ & $n$ & $\mathrm{SIR}(\mathrm{Cl})$ \\
\hline Thiazide & 16 & $0.9(0.5-1.5)$ & 12 & $0.9(0.5-1.6)$ & 4 & $0.8(0.2-2.2)$ \\
\hline Loop diuretic & 104 & $1.5(1.3-1.9)$ & 76 & $1.6(1.2-2.0)$ & 28 & $1.5(1.0-2.1)$ \\
\hline Beta blocker & 47 & $1.0(0.7-1.3)$ & 32 & $1.0(0.7-1.3)$ & 15 & $1.0(0.6-1.6)$ \\
\hline Calcium channel blocker & 38 & $1.0(0.7-1.4)$ & 30 & $1.1(0.7-1.5)$ & 8 & $0.8(0.3-1.5)$ \\
\hline ACE inhibitor & 29 & $1.0(0.7-1.5)$ & 24 & $1.3(0.8-1.9)$ & 5 & $0.5(0.2-1.2)$ \\
\hline ACE inhibitor/Thiazide & 2 & $0.4(0.1-1.6)$ & 2 & $0.6(0.1-2.2)$ & 0 & - \\
\hline Angiotensin II receptor blocker & 11 & $1.0(0.5-1.8)$ & 11 & $1.0(0.5-1.8)$ & 0 & - \\
\hline Angiotensin II receptor blocker/Thiazide & 10 & $0.5(0.2-0.9)$ & 8 & $0.5(0.2-1.1)$ & 2 & $0.4(0-1.4)$ \\
\hline
\end{tabular}

SIR Standardized Incidence Ratio

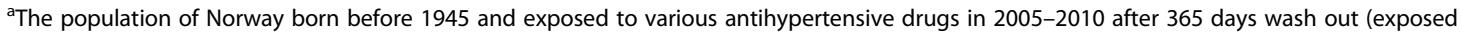
person-days, 14 days)

decided not to use drugs as proxies of comorbidities. The Norwegian Prescription Database includes reimbursement codes for drugs prescribed for chronic conditions, linked to ICD-10 diagnoses. We did not consider this information because reimbursement codes were neither validated nor complete (selected drugs only) and not available before 2009. Previous studies generally revealed protective associations between hip fracture and antihypertensive drugs to remain when adjusting for comorbidity, socioeconomic factors, life style and concomitant drug use $[25,26]$; loop diuretics, however, were sensitive for adjustment [26].

Because antihypertensive drugs are predominantly used on a daily basis, we considered the number of days corresponding to the number of DDDs dispensed the best proxy for the number of drug-exposed person-days. A study in Germany observed the actually prescribed mean daily dose (PDD) to be nearly 2.0 DDD for ACE inhibitors and angiotensin II receptor blockers and close to 1.0 DDD for beta-blockers, calcium-channel blockers and thiazides [27]. Consequently, we may have overestimated the exposed person-time, and thus the strength of the associations between ACE inhibitors and angiotensin II receptor blockers, and the risk of hip fractures.

Health care in Norway is public and tax-financed; very low out-of-pocket money and good reimbursement systems may explain the greater use of newer and more expensive antihypertensive drugs in Norway compared to other countries in Europe and North America [9]. One could suspect that the indication and frequency of treatment with antihypertensive drugs differs in a public health care setting and a setting with insurance based health care.

\section{Antihypertensive drugs and hip fracture}

Different mechanisms have been postulated for effects of antihypertensive drugs on fracture risk depending on the duration of drug use; through hypotension and falls in recently started treatment and through changes in bone metabolism and bone strength in long-term treatment [26]. In addition to direct (falls) and indirect (BMD) drug effects, treatment of the underlying cardiovascular disease may possible reverse its negative effects on bone quality and contribute to reduction in fracture risk.

\section{Renin-angiotensin-aldosterone active agents}

We found the risk of hip fracture to be decreased with angiotensin II receptor blockers (plain and combination products); use of ACE inhibitors was associated with increased risk among users aged $<80$ years and decreased among those 80 years and older. The human studies conducted previously have provided conflicting evidence regarding the effects of ACE inhibitors on bone metabolism and fracture risk, whereas angiotensin II receptor blockers appear to be osteoprotective. A population-based casecontrol study in Denmark reported a $14 \%$ reduction in hip fracture risk (adjusted OR 0.86, $95 \%$ CI 0.80-0.92) in users of ACE inhibitor compared with nonusers; the crude OR was not significant. There were no major differences according to sex, age and drug dosage [25]. Another casecontrol study in the United Kingdom revealed a decreased risk of any fracture for longer-term current users $(\geq 20$ prescriptions) of ACE inhibitors (adjusted OR, 0.81; $95 \%$ CI 0.73-0.89), though, subanalysis for hip fracture was not conducted. No difference in fracture risk was found with use of angiotensin II receptor blockers [28]. In a large cohort study among low-income older people the United States, new use of angiotensin II receptor blockers was associated with a reduction in hip fracture risk (adjusted Hazard Ratio, HR 0.77, 95 \% CI 0.64-0.93) compared with calcium channel blockers (reference exposure), whereas no trend was observed for ACE inhibitors (HR 0.95, $95 \%$ CI 0.84-1.07). Of note, nonusers were not considered, and 
wash out period (30 days) and follow-up period (median 70 days) were short [26]. In a population-based cohort study in Sweden, use of renin-angiotensin-aldosterone active agents was not associated with altered risk of hip fracture (adjusted OR 0.93, 95 \% CI 0.79-1.09); however, separate analyses for ACE inhibitors and angiotensin II receptor blockers were not conducted [29]. Another population-based cohort study in Canada failed to demonstrate significant differences in hip fracture risk in hypertensive older people treated with angiotensin II receptor blockers compared to ACE inhibitors (adjusted HR 0.99, $95 \%$ CI 0.78-1.25); nonusers were not considered [30]. The Hypertension in the Very Elderly Trial (HYVET), a randomized trial with hip fracture as a secondary outcome measure, revealed that treatment with a thiazide-like diuretic $\pm \mathrm{ACE}$ inhibitor may reduce the risk of hip fracture [31]. To the best of our knowledge, previous research has not included combination products. We found protective associations of ACE inhibitor/thiazide and angiotensin II receptor blocker/thiazide with hip fracture to be stronger than for the individual drugs involved. This may possibly be due to several interacting, beneficial effects on underlying cardiovascular disease and bone strength.

A cross-sectional study of hypertensive Chinese men and women reported associations between ACE inhibitor use and higher BMD at the hip, after adjusting for diagnoses, medications and lifestyle [32]. This finding was not confirmed by a more recent prospective cohort study in the United States; ACE inhibitors were associated with hip bone loss whereas angiotensin II receptor blockers were not [33]. An open randomized trial showed beneficial effects of ACE inhibitors \pm thiazide in hypertensive people, i.e. BMD loss was avoided and metabolic profile was improved. Subgroup analysis for ACE polymorphism revealed that beneficial $\mathrm{BMD}$ response was confined to women with the DD polymorphism [34]. Another open randomized study demonstrated that angiotensin II receptor blockers inhibited bone loss and increased BMD at the hip in older bed-ridden women, as compared to calcium channel blockers [35]. In vitro, angiotensin I stimulates bone resorption in co-cultures of osteoblast and osteoclasts, and this action is inhibited by ACE inhibitors [36]. Angiotensin II accelerates bone resorption by activating osteoclasts, whereas these effects are blocked by angiotensin II receptor blockers [37]. Hence, animal studies suggest that renin-angiotensin-aldosterone active agents inhibit bone resorption, rather than stimulate bone formation [37, 38].

\section{Calcium channel blockers}

Our finding of a reduced fracture risk among users of calcium channel blockers is partly in line with the abovementioned epidemiologic studies conducted in Denmark and Sweden. Rejnmark et al. reported a small reduction in hip fracture risk by 7 \% (adjusted OR 0.93, 95 \% CI 0.87-
0.99) [25] while Thorell et al. found a reduction by $18 \%$ (crude OR 0.82, 95 \% CI 0.68-0.98); the differences in the latter study were not maintained, however, after adjustment for age, sex and comorbidity [29]. Although in vitro studies suggest that calcium-channel blockers may inhibit osteoclast function [38], previous research has found no association with hip BMD [32].

\section{Thiazides}

Our findings of a reduced hip fracture risk among thiazideusers align with a Cochrane review including 6 cohort and 15 case-control studies; compared with nonusers, the fracture risk among thiazide users was decreased by $24 \%$, relative risk (RR) 0.76 (95\% CI 0.64-0.78) [39]. Randomized controlled trials have revealed preservation of cortical bone in older women and men using thiazides, however, fracture was not an outcome measure [40, 41]. Beneficial effects on $\mathrm{BMD}$ are probably caused by increased renal calcium absorption, suppressed parathyroid hormone secretion and enhanced calcium uptake in the intestine, leading to a positive calcium balance. Further, thiazides directly affect bone by stimulating osteoblast differentiation [15].

\section{Loop diuretics}

The results of our study suggest that risk of hip fracture with loop diuretics changes with the users' age; fracture risk being increased among users aged $<80$ years, and decreased among those 80 years and older. A meta-analysis of 4 cohort and 9 case-control studies reported a $14 \%$ increase in overall risk of hip fracture among loop diuretic users compared with nonusers, RR 1.14 (95 \% CI 1.081.19) [42]. However, most included studies were adjusted for age, not allowing for comparison between different age groups. Some studies have reported sensitivity of risk estimates to adjustment for other confounders (e.g. prior fracture, comorbidity or use of other drugs), revealing smaller RRs after adjustment [26, 43]. Cohort studies and a randomized controlled trial have reported loss of total hip BMD among older women and men using loop diuretics compared with nonusers [44-46]. Interestingly, a recent study indicated a clinical association of hyponatremia during loop diuretic use and an increased risk of osteoporotic fractures, possible due to exertion of loss of bone sodium and calcium [47].

\section{Beta-blockers}

We found the risk of hip fracture to be decreased with use of beta-blockers, in accordance with two meta-analyses. Yang et al. (6 cohort and 7 case-control studies) reported reduction in risk by $17 \%$ (RR $0.83,95 \%$ CI $0.70-0.92$ ) [48], and Toulis et al. (7 cohort and 9 case-control studies) reduction by $14 \%$ in women (pooled effect size (ES) $0.86,95 \%$ CI $0.80-0.91$ ) and $20 \%$ in men (ES 0.80, $95 \%$ CI 0.71-0.90) [49]. Although observational studies have 
associated use of beta-blockers with a higher BMD at the hip [50-52], randomized trials are lacking. Several studies suggest the reduction in hip fracture risk to be associated with $\beta 1$-selective agents rather than nonselective betablockers $[49,53]$. The underlying mechanisms are not yet clear. Increased sympathetic nervous activity causes an increase in bone resorption and a decrease in bone formation through stimulation of osteoclasts and inhibition of osteoblasts. In vitro studies suggest that beta-blockers enhance bone formation through blocking input from the sympathetic nervous system [54].

\section{Recently started drug use}

We found increased risk of hip fracture during the first 2 weeks of treatment with loop diuretics; similar findings have been reported by Berry et al. for the initial 3 weeks of treatment with thiazides and loop diuretics [12], and by Butt et al. for the 45 days immediate after a first prescription of various antihypertensive drugs (incidence rate ratio 1.43, $95 \%$ CI 1.19-1.72) [11]. Although the numbers of hip fractures in these studies were relatively small and the findings must be interpreted with caution, the results are interesting because they are opposite to those with longterm drug use. Whereas initiating antihypertensive drugs is known as risk factor for falls in older people [11], two meta-analyses revealed no significant associations of falls with current use of antihypertensive drugs $[13,14]$. On the other hand, a recent population-based study found a doseresponse relationship between drug dose and falls [55].

\section{Age and sex}

We found a lower risk of hip fracture among exposed men than among exposed women. Rejnmark et al. reported similar trends for sex with regard to beta-blockers, ACE inhibitors and calcium channel blockers [25]. Sex hormones interfere with bone metabolism, posing postmenopausal women at a much higher risk of hip fracture than men; most antihypertensive drugs appear to be beneficial for bone health in both sexes, however, risk differences are not eliminated.

Generally, we found the protective associations to be most evident within the youngest cohorts. We probably underestimated the risk of hip fracture among the oldest old because the lack of clinical information (confounding factors could not be adjusted for) and the systematic misclassification of the highly exposed [22] nursing home patients as drug non-users. Amplification of the effects of these drugs with advancing age may suggest the maintenance of protective drug effects despite other risk factors such as frailty, osteoporosis, comorbidity and concomitant drug use. On the other hand, cessation of drug treatment in the oldest age groups could be associated with general clinical deterioration (the "healthy user effect"), explaining the SIRs below 1. The increased hip fracture risk in people younger than 80 years using loop diuretics and plain ACE inhibitors, however, may possibly be due to the "more-illuser effect" as these drugs are frequently issued to relatively frail people with heart failure.

\section{Conclusions}

Our findings support that older people using antihypertensive drugs are at a lower risk of hip fracture compared with people not using these drugs. Fracture risk among users of loop diuretics and ACE inhibitors younger than 80 years, however, was increased. This may have great impact at the population level, because the use of antihypertensive drugs is widespread in people at risk of hip fracture. Clinical studies are needed to further explore these associations. Even though antihypertensive drugs might be protective against hip fracture, prescribers should carefully consider increased vulnerability to hemodynamic side effects when initiating treatment in older people and practice the key principle: "start low and go slow."

\section{Additional file}

Additional file 1: Number of people in Norway born before 1945 by birth cohort and sex distribution. (DOC $29 \mathrm{~kb}$ )

\section{Competing interests}

The authors declare that they have no competing interests.

\section{Authors' contributions}

All authors contributed to the definition of the research question, the design of the study and the interpretation of the results. SR obtained approvals and acquired data, AE conducted the statistical analyses. SR wrote the first draft of the manuscript, which MSB, AE, AHR, SH and AE helped to finalize. All authors read and approved the final manuscript.

\section{Author details}

${ }^{1}$ Department of Global Public Health and Primary Care, University of Bergen, PO Box 7804, N-5020 Bergen, Norway. ${ }^{2}$ Research Unit for General Practice, Uni Research Health, Bergen, Norway. ${ }^{3}$ Kavli Research Centre for Geriatrics and Dementia, Haraldsplass Deaconess Hospital, Bergen, Norway.

${ }^{4}$ Department of Clinical Science, University of Bergen, Bergen, Norway. ${ }^{5}$ National Centre for Emergency Primary Health Care, Uni Research Health, Bergen, Norway. ${ }^{6}$ Department of Clinical Medicine, University of Bergen, Bergen, Norway. ${ }^{7}$ Norwegian Arthroplasty Registry, Department of Orthopaedics, Haukeland University Hospital, Bergen, Norway. ${ }^{8}$ Department of Pharmacoepidemiology, Norwegian Institute of Public Health, Oslo, Norway.

Received: 5 July 2015 Accepted: 23 November 2015

Published online: 01 December 2015

\section{References}

1. Leibson CL, Tosteson AN, Gabriel SE, Ransom JE, Melton LJ. Mortality, disability, and nursing home use for persons with and without hip fracture: a population-based study. J Am Geriatr Soc. 2002;50:1644-50.

2. Ahmed LA, Schirmer H, Bjørnerem $\AA$, Emaus N, Jørgensen L, Størmer J, et al. The gender- and age-specific 10-year and lifetime absolute fracture risk in Tromsø, Norway. Eur J Epidemiol. 2009;24:441-8.

3. Gangavati A, Hajjar I, Quach L, Jones RN, Kiely DK, Gagnon P, et al. Hypertension, orthostatic hypotension, and the risk of falls in a community-dwelling elderly population: the maintenance of balance, independent living, intellect, and zest in the Elderly of Boston Study. J Am Geriatr Soc. 2011;59:383-9. 
4. Cappuccio FP, Meilahn E, Zmuda JM, Cauley ZA. High blood pressure and bone-mineral loss in elderly white women: a prospective study. Study of Osteoporotic Fractures Research Group. Lancet. 1999;354:971-5.

5. Pérez-Castrillón JL, Martín-Escudero JC, Alvarez Manzanares P, Cortés Sancho R, Iglesias Zamora S, García Alonso M. Hypertension as a risk factor for hip fracture. Am J Hypertens. 2005;18:146-7.

6. Sennerby U, Melhus K, Gedeborg R, Byberg L, Garma H, Ahlbom A, et al. Cardiovascular diseases and risk of hip fractures. JAMA. 2009;302:1666-73.

7. Norwegian Prescription Database [http://norpd.no].

8. Blix HS, Landmark K, Selmer R, Reikvam A. Patterns in the prescription of antihypertensive drugs in Norway, 1975-2010. Tidsskr Nor Laegeforen. 2012;132:1224-8.

9. Fretheim A, Oxman AD. International variation in prescribing antihypertensive drugs: its extent and possible explanations. BMC Health Serv Res. 2005;5:21.

10. Butt DA, Mamdani M, Austin PC, Tu K, Gomes T, Glazier RH. The risk of falls on initiation of antihypertensive drugs in the elderly. Osteoporos Int. 2013; 24:2649-57.

11. Butt DA, Mamdani M, Austin PC, Tu K, Gomes T, Glazier RH. The risk of hip fracture after initiating antihypertensive drugs in the elderly. Arch Intern Med. 2012;172:1739-44.

12. Berry SD, Zhu Y, Choi H, Kiel DP, Zhang Y. Diuretic initiation and the acute risk of hip fracture. Osteoporos Int. 2013;24:689-95.

13. Leipzig RM, Cumming RG, Tinetti ME. Drugs and falls in older people: a systematic review and meta-analysis. II. Cardiac and analgesic drugs. J Am Geriatr Soc. 1999:47:40-50.

14. Woolcott JC, Richardson KJ, Wiens MO, Patel B, Marin J, Khan KM, et al. Meta-analysis of the impact of 9 medication classes on falls in elderly persons. Arch Intern Med. 2009;169:1952-60.

15. Ghosh M, Majundar SR. Antihypertensive medications, bone mineral density, and fractures: a review of cardiac drugs that provides new insights into osteoporosis. Endocrine. 2014;46:397-405.

16. Gjertsen JE, Engesaeter LB, Furnes O, Havelin LI, Steindal K, Vinje T, et al. The Norwegian Hip Fracture Register: experiences after the first 2 years and 15,576 reported operations. Acta Orthop. 2008;79:583-93.

17. Norwegian Central Population Registry [http://www.skatteetaten.no/en/ Person/National-Registry/?utm_source=1\&utm_medium=flyttemelding\&utm_ campaign=folkeregisteret].

18. Bakken MS, Engeland A, Engesæter LB, Ranhoff AH, Hunskaar S, Ruths S. Increased risk of hip fracture among older people using antidepressant drugs: data from the Norwegian Prescription Database and the Norwegian Hip Fracture Registry. Age Ageing. 2013;42:514-20.

19. Furu K. Establishment of the nationwide Norwegian Prescription Database. Nor J Epidemiol. 2008;18:129-36.

20. The WHO Collaborating Centre for Drug Statistics Methodology [http://www. whocc.no/atc_ddd_index/].

21. Engeland A, Skurtveit S, Morland J. Risk of road traffic accidents associated with the prescription of drugs: a registry-based cohort study. Ann Epidemiol. 2007;17:597-602.

22. Nygaard HA, Naik M, Ruths S, Straand J. Nursing-home residents and their drug use: a comparison between mentally intact and mentally impaired residents. The Bergen district nursing home (BEDNURS) study. Eur J Clin Pharmacol. 2003;59:463-9.

23. Rapp K, Becker C, Lamb SE, Icks A, Klenk J. Hip fractures in institutionalized elderly people: incidence rates and excess mortality. J Bone Miner Res. 2008; 23:1825-31.

24. Norwegian Arthroplasty Register. 2015. Annual report (2014) available from: http://nrlweb.ihelse.net.

25. Rejnmark L, Vestergaard P, Mosekilde L. Treatment with beta-blockers, ACE inhibitors, and calcium-channel blockers is associated with a reduced fracture risk: a nationwide case-control study. J Hypertens. 2006;24:581-9.

26. Solomon DH, Mogun H, Garneau K, Fischer MA. Risk of fractures in older adults using antihypertensive medications. J Bone Miner Res. 2011;26:1561-7.

27. Grimmsmann T, Himmel W. Discrepancies between prescribed and defined daily doses: a matter of patients or drug classes? Eur J Clin Pharmacol. 2011; 67:847-54.

28. Schlienger RG, Kraenzlin ME, Jick SS, Meier CR. Use of $\beta$-blockers and risk of fractures. JAMA. 2004;292:1326-32.

29. Thorell K, Ranstad K, Midlöv P, Borgquist L, Halling A. Is use of fall-increasing drugs in an elderly population associated with an increased risk of hip fracture, after adjustment for multimorbidity level: a cohort study. BMC Geriatr. 2014;14:131.
30. Butt DA, Mamdani M, Gomes T, Lix L, Lu H, Tu K. Risk of osteoporotic fractures with angiotensin II receptor blockers versus angiotensin-converting enzyme inhibitors in hypertensive community-dwelling elderly. J Bone Miner Res. 2014;29:2483-8.

31. Peters R, Beckett N, Burch L, de Vernejoul MC, Liu L, Duggan J, et al. The effect of treatment based on a diuretic (indapamide) \pm ACE inhibitor (perindopril) on fractures in the Hypertension in the Very Elderly Trial (HYVET). Age Ageing. 2010;39:609-16.

32. Lynn H, Kwok T, Wong SY, Woo J, Leung PC. Angiotensin converting enzyme inhibitor use is associated with higher bone mineral density in elderly Chinese. Bone. 2006;38:584-8.

33. Kwok T, Leung J, Zhang YF, Bauer D, Ensrud KE, Barrett-Connor E, et al. Does the use of ACE inhibitors or angiotensin receptor blockers affect bone loss in older men? Osteoporos Int. 2012;23:2159-67.

34. Pérez-Castrillón JL, Silva J, Justo I, Sanz A, Martín-Luquero M, Igea R, et al. Effect of quinapril, quinapril.-hydrochlorothiazide, and enalapril on the bone mass of hypertensive subjects: relationship with angiotensin converting enzyme polymorphism. Am J Hypertens. 2003;16:453-9.

35. Aoki M, Kawahata H, Sotobayashi D, Yu H, Moriguchi A, Nakagami H, et al, Effect of angiotensin II receptor blocker, olmesartan, on turnover of bone metabolism in bedridden elderly hypertensive women with disuse syndrome. Geriatr Gerontol Int. 2014. doi: 10.1111/ggi.12406.

36. Shimizu H, Nakagami H, Osako MK, Nakagami F, Kunugiza Y, Tomita T, et al. Prevention of osteoporosis by angiotensin-converting enzyme inhibitor in spontaneous hypertensive rats. Hypertens Res. 2009;32:786-90.

37. Shimizu H, Nakagami H, Osako MK, Hanayama R, Kunugiza Y, Kizawa T, et al. Angiotensin II accelerates osteoporosis by activating osteoclasts. FASEB J. 2008:22:2465-75.

38. Gradosova I, Zivna H, Palicka V, Hubena S, Svejkovska K, Zivny P. Protective effect of amlodipine on rat bone tissue after orchidectomy. Pharmacology. 2012;635:37-43.

39. Aung K, Htay T. Thiazide diuretics and the risk of hip fracture. Cochrane Database Syst Rev. 2011;10:CD005185.

40. Reid IR, Ames RW, Orr-Walker BJ, Clearwater JM, Horne AM, Evans MC, et al. Hydrochlorothiazide reduces loss of cortical bone in normal postmenopausal women: a randomized controlled trial. Am J Med. 2000; 109:362-70.

41. LaCroix AZ, Ott SM, Ichikawa L, Scholes D, Barlow WE. Low-dose hydrochlorothiazide and preservation of bone mineral density in older adults. A randomized, double-blind, placebo-controlled trial. Ann Intern Med. 2000;133:516-26.

42. Lim LS, Fink HA, Blackwell T, Taylor BC, Ensrud KE. Loop diuretic use and rates of hip bone loss and risk of falls and fractures in older women. J Am Geriatr Soc. 2009;57:855-62.

43. Reinmark L, Vestergaard P, Heickendorff L, Andreasen F, Mosekilde L. Loop diuretics increase bone turnover and decrease BMD in osteopenic postmenopausal women: results from a randomized controlled study with bumetanide. J Bone Miner Res. 2006;21:163-70.

44. Xiao F, Qu X, Zhai Z, Jiang C, Li H, Liu X, et al. Association between loop diuretic use and fracture risk. Osteoporos Int. 2014 Dec 10 [Epub ahead of print] DOI 10.1007/s00198-014-2979-8

45. Rejnmark $L$, Vestergaard $P$, Mosekilde L. Fracture risk in patients treated with loop diuretics. J Int Med. 2006;259:117-24.

46. Lim LS, Fink HA, Kuskowski MA, Taylor BC, Schousboe JT, Ensrud KE. Loop diuretic use and increased rates of hip bone loss in older men: the Osteoporotic Fractures in Men Study. Arch Intern Med. 2008;168:735-40.

47. Arampatzis S, Gaetcke LM, Funk GC, Schwarz C, Mohaupt M, Zimmermann $\mathrm{H}$, et al. Diuretic-induced hyponatremia and osteoporotic fractures in patients admitted to the emergency department. Maturitas. 2013;75:81-6.

48. Yang S, Nguyen ND, Eisman JA, Nguyen TV. Association between beta-blockers and fracture risk: a Bayesian meta-analysis. Bone. 2012;51:969-74.

49. Toulis KA, Hemming K, Stergianos S, Nirantharakumar K, Bilezikian JP. $\beta$-adrenergic receptor antagonists and fracture risk: a meta-analysis of selectivity, gender, and site-specific effects. Osteoporos Int. 2014;25:121-9.

50. Pasco JA, Henry MJ, Sanders KM, Kotowicz MA, Seeman E, Nicholson GC. Beta-adrenergic blockers reduce the risk of fracture partly by increasing bone mineral density: Geelong Osteoporosis Study. J Bone Miner Res. 2004; 19:19-24.

51. Reid IR, Gamble GD, Grey AB, Black DM, Ensrud KE, Browner WS, et al. Beta-blocker use, BMD, and fractures in the study of osteoporotic fractures. J Bone Miner Res. 2005;20:613-8. 
52. Yang S, Nguyen ND, Center JR, Eisman JA, Nguyen TV. Association between beta-blockers and fracture risk: the Dubbo Osteoporosis Epidemiology Study. Bone. 2011:48:451-5

53. Song HJ, Lee J, Kim YJ, Jung SY, Kim HJ, Choi NK, et al. $\beta 1$ selectivity of $\beta$-blockers and reduced risk of fractures in elderly hypertension patients. Bone. 2012;51:1008-15.

54. Rodrigues WF, Madeira MF, da Silva TA, Clemente-Napimoga JT, Miguel CB, Dias-da-Silva VJ, et al. Low dose of propranolol down-modulates bone resorption by inhibiting inflammation and osteoclast differentiation. $\mathrm{Br}$ J Pharmacol. 2012;165:2140-51.

55. Callisaya ML, Sharman JE, Close J, Lord SR, Srikanth VK. Greater daily defined dose of antihypertensive medication increases the risk of falls in older people-A population-based study. J Am Geriatr Soc. 2014;62:1527-33.

Submit your next manuscript to BioMed Central and we will help you at every step:

- We accept pre-submission inquiries

- Our selector tool helps you to find the most relevant journal

- We provide round the clock customer support

- Convenient online submission

- Thorough peer review

- Inclusion in PubMed and all major indexing services

- Maximum visibility for your research 